Original Research Paper

\title{
Construction Stage Analysis for a New Mixed Structure Building in Milan
}

\author{
${ }^{1}$ Marco Zucca, ${ }^{1}$ Nicola Longarini, ${ }^{2}$ Federico de Socio and ${ }^{2}$ Iacopo Migliori \\ ${ }^{I}$ Department of Architecture Built Environment and Construction Engineering, Politecnico di Milano, Italy \\ ${ }^{2}$ E-Copla Engineering, Milan, Italy
}

\author{
Article history \\ Received: $30-01-2018$ \\ Revised: 22-02-2018 \\ Accepted: 5-03-2018 \\ Corresponding Author: \\ Marco Zucca \\ Department of Architecture \\ Built Environment and \\ Construction Engineering, \\ Politecnico di Milano, Italy \\ Email: marco.zucca@polimi.it
}

\begin{abstract}
In this study the Construction Stage Analysis (CSA) of a new mixed structure building is discussed in order to identify the best timing and execution activities scheduling. The building is part of a new university campus that will be realized close to the center of the city. The CSA is carried out by the implementation of two models: the finite element model for the structural analyses and the BIM model for controlling the sequence of the construction phases. Once fixed the structural model, in the preliminary design phase, different sequences are analyzed in order to optimize the construction management in terms of timing and costs. Moreover, the optimization of the construction phases is set by considering the creep and shrinkage of the concrete material.
\end{abstract}

Keywords: BIM, Construction Management, Structural Analysis

\section{Introduction}

In this study the influence of the Construction Stage Analysis (CSA) on various aspects of the process, structural choices, scheduling of the activities (to achieve a better timing and quality) is discussed.

The studied building, realized by a mixed steelconcrete structure, is a part of a new University Campus located in Milan. The building will have dormitory function.

The CSA is carried out by using a FEM software combined with a BIM software.

Through the FEM, it is possible to analyze the construction stages of the building. The Construction Stage Analysis is useful in order to study the stress condition during each phases and for understanding the different behavior of the structure either in terms of stresses and deformations. In fact, with this type of analysis, it is possible to obtain a number of transitional checks in order to evaluate the correct and safe development of the yard because, usually, in a classic study, it is supposed that the final stage is the worst stress condition of the building, but it is not always so.

The Construction Stage approach gives the possibility to extrapolate the difference between the deformations that are exhausted at the end of the structure completion and the total deformations due to the additional operating loads. That difference represents the real deformation which non-structural elements resemble, instead of the total deformation, that it is much larger.
It has been attributed, by using CEB-FIP Model Code 2010, the time dependence to the concrete behavior as to simulate creep, shrinkage and increasing of compressive strength in the first 28 days from casting. This has allowed to improve the precision of stress conditions and deformations evaluation of the structural elements during each phase. Consequently, it is possible, for example, to analyze the loading stages of props.

The BIM implementation for the CSA, here divided in construction stages, follows the site evolution, from the excavation till the end of the structure realization. BIM Model is more useful if combined with the finite element one. All the information obtained with the FEM software can be transferred, using BIM, directly on site. The purpose of this information transfer is to accurately manage each realization phase of the building, speeding up the constructive process while simultaneously improving the quality of the facility (Sacks et al., 2010).

\section{Building Description}

The architectural choices have strongly influenced the structural requirements related to the technical solutions through a preliminary conceptual design. Below, the individual problems encountered during this process will be treated one by one.

One of the points that most characterizes this building is to reach $35 \mathrm{~m}$ height, as can be seen in Fig. 1 and 2, which shows the structural section. The building is the highest of the entire Campus, it has ten stories for accommodating 300 beds. 


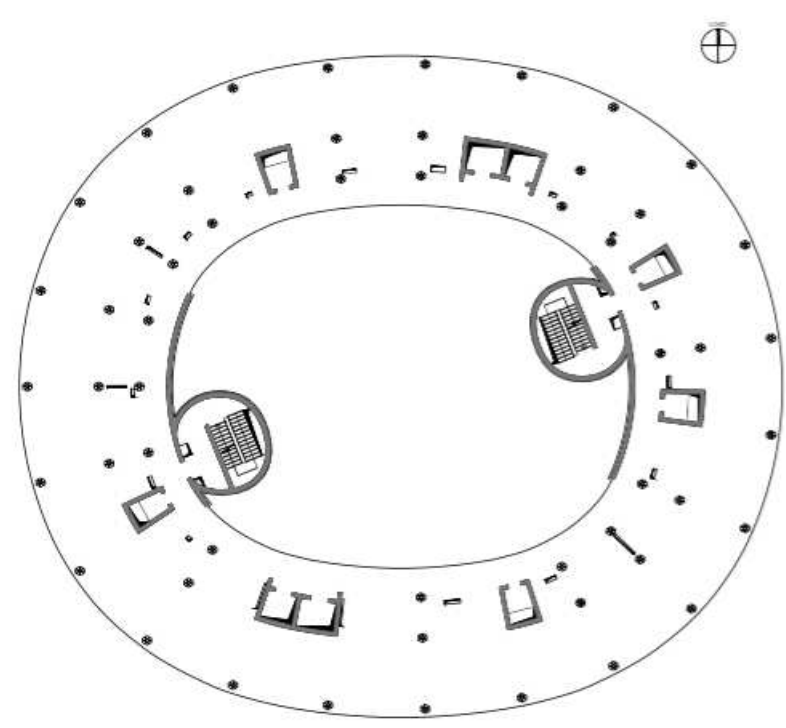

Fig. 1: Building type floor

Therefore, the structural system is a mixed system steel-concrete:

- walls are realized with C28/35 concrete class and reinforced by steel bars $\mathrm{B} 450 \mathrm{C}$. They have to resist to the horizontal actions. Their in-plan positioning was coupled with the need to create four elevator compartments, two stairwells and various technical premises;

- columns are realized by S355 steel class and a decreasing circular section with height. As opposed to the walls, their main function is to resist to the vertical loads.

The final shape of the plan is the result of architectural necessities, to recall the curvilinear forms of adjacent buildings (and functional necessities) as it was intended to provide adequate natural lighting for the internal spaces. The in-plane shape is an elliptical hollow form, as shown from Fig. 1 and 2, which allows for both interior and exterior appearance. In addition, to maximize the amount of natural light, all the walls have not been placed close the façade, unless in a small area (Serena, 2012).

The particular shape of the plan has caused a decrease in the possible technical alternatives to realize the slabs. In order to make a choice that permits the maximum shape flexibility, designers have opted for a solid reinforced concrete slab cast on site, realized with the same materials of walls (C28/35 concrete class and B450C steel bars). This solution has also been able to cover the large spans, over $7 \mathrm{~m}$, between the vertical supports, without using beams with higher height than the slab. The absence of beams permits a thickness minimization for the technology package used for the ceiling. Thus, optimizing the available space for each story, it has been possible to obtain the higher number of total story.

In addition, the use of a solid reinforced concrete slab, ensures the perfect behavior of the slab as rigid plan. This behavior properly distributes all the horizontal forces, absorbed by the building, to elements with greater inertia, like the walls.

Another feature requested by the Client is a large parking area, that is placed just under the building, in the basement. However, the configuration of the columns placed on superior stories would not allow enough width to create the internal lane to reach each parking. This problem has been solved by interrupting the columns of the first floor on a beam without directly achieve the ground. The reinforced concrete beams, cast on site, must be highly resistant with an appropriate section and inertia. With this solution the load is carried to the soil by the walls at the two ends of these beams.

As for the inner columns, they transmit their load directly on the basement walls (located at the parking floor) just underneath their support point.

Finally, the foundation system is a characterized by reinforced concrete platform, realized with the same materials of the other concrete elements. The choice of a platform solution comes out from the necessity to minimize the stresses transmitted from the structure to the non-cohesive soil. The platform distributes the stresses on a bigger area with respect to other solutions, so it consequently reduces the absolute and relative yields ensuring a better behavior of all the structure.

Below, the plan and the section of the studied building, resulted from the described choices, are shown.

\section{Construction Stage Analysis - from BIM to FEM}

In addition to FEM, it has been developed a BIM model. The aim of this coupling is to have the control on the construction phases, in Fig. 3 and 4 is shown an example of the same phase implemented in both software.

This study involves all the construction phases that characterize the elevation of the building: From the foundation to the roof. All the slabs are characterized by massive castings which are supported by a formwork system.

The production rate of the site expect the realization of a story every 15 days (both elevation structures and slabs). Therefore, in the CSA on FEM software, a 7day time period was allocated to the realization of elevation structures; 8-days on the works related to the realization of slabs.

The props of a floor, modeled on both software, are placed before the realization of the slab and will be removed when the two upper floors are made and propped up by other props. 
Marco Zucca et al. / International Journal of Structural Glass and Advanced Materials Research 2018, Volume 2: 66.72 DOI: $10.3844 /$ sgamrsp.2018.66.72

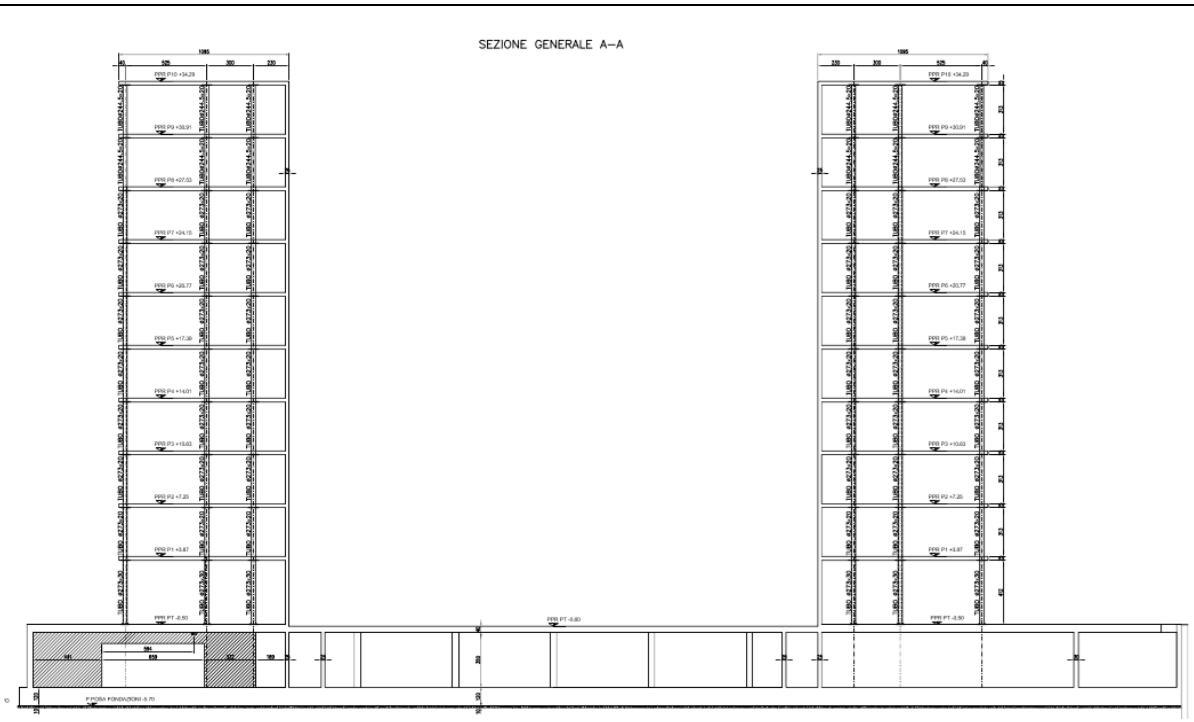

Fig. 2: Building section

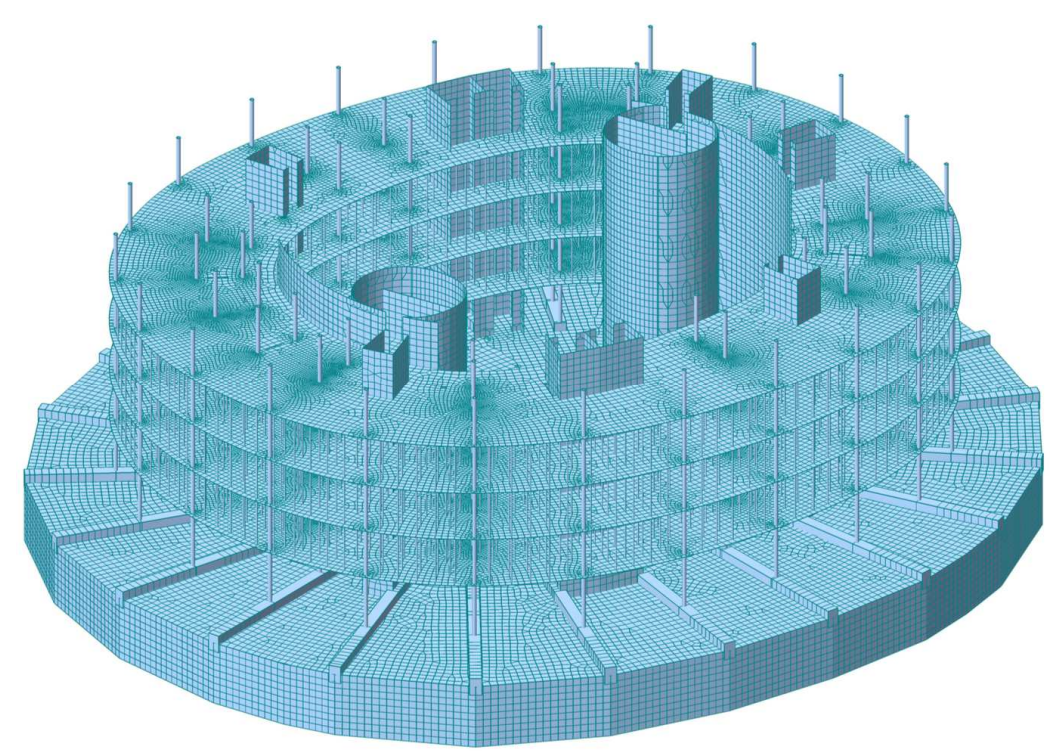

Fig. 3: FEM model

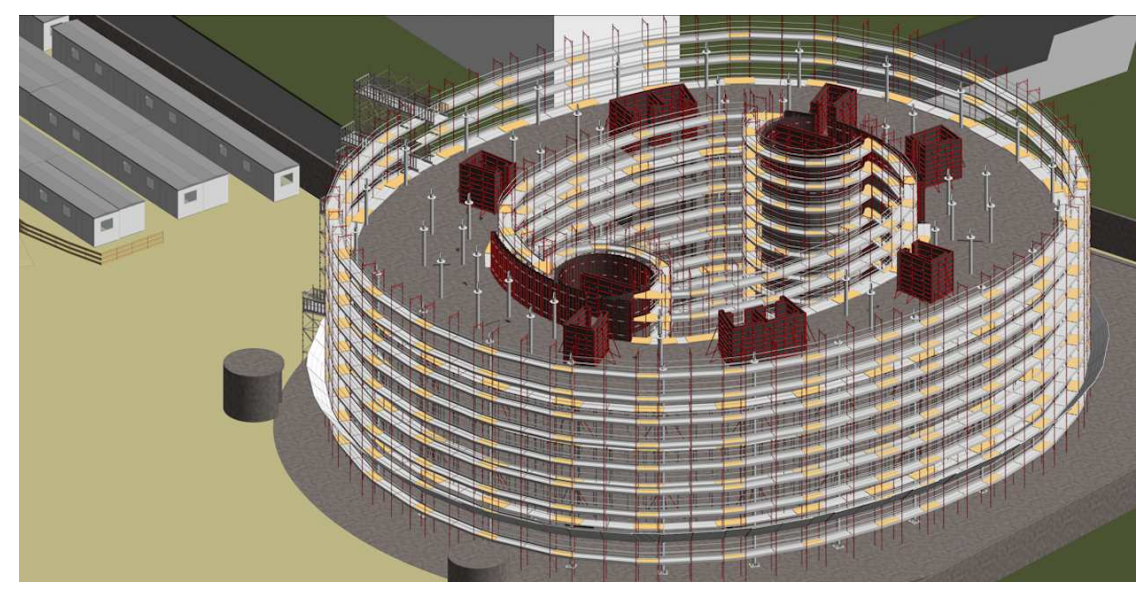

Fig. 4: BIM model 
In the FEM software, the functions describing actual concrete performances are introduced. The functions (CEB-FIB, 2010) reproduce how creep, shrinkage and the increase of compressive strength influence the evolution of the structure. Particularly, the last of these three phenomena makes it possible to appreciate the parallel increase in resistance and elastic modulus of the concrete, during the 28 days of maturation.

These three functions are useful to obtain results of stresses and deformations of structural elements in every moment during the construction. Consequently, transient structural checks can be carried out.

Once all the information necessary for the correct development of the building has been obtained, the BIM model becomes useful to transfer them directly to the site, in the exact phase in which they are needed. This operation is performed by combining a BIM card, shown in Fig. 5, to each element in the model, both structural or not. In these cards are shown all the information regarding the element, that come from FEM model, technical data sheets or other sources.

\section{Transient Study of on Ground Floor Props}

Through FEM, it is possible to verify the correct design and the best choice of the props section and number, used to hold up the slab during transitory phases. These elements are modeled in the Finite Element Software using beam elements. Thanks to this kind of study it was possible to evaluate props' maximum load before their removing.

Figure 6 shows the phase after the realization of the third slab.

After thirty days from the execution of the first floor, the maximum value of the axial force acting on the ground floor prop is equal to $38,9 \mathrm{kN}$, slightly less than the maximum axial resistance of $40 \mathrm{kN}$, certified by the manufacturer. This maximum allowable load concerns only the props of the ground floor. In fact, it was decided to analyze specifically only the on ground floor props as, having to reach a higher height, they have a lower allowable.

The props that undergoes this great effort is located far from the elevation structures with greater axial stiffness, approximately in the center of the slab span. Consequently, to optimize the number of the props, on one hand a major density of them must be positioned in the center of the spans, on the other hand just few of them must be positioned close to elevation structures.

Figure 7 shown the next step during CSA, where the ground floor props are removed.

The trend of the load regarding the maximum loaded prop shows that:

- In the first stage, which represents the moment of the first floor casting, the concrete of the P1 slab, having not developed flexural rigidity, acts as a ballast, burdens on the underlying vertical elements, according to their specific areas of influence. It has been possible to see that at the end of the first stage, props and pillars, are loaded with the same value of normal effort

- In the second and third stage, representing the moments of second and third floor casting, it was possible to see how the P1 slab, having developed much of its resistance. It behaves as a distribution element, with its flexural rigidity, that transmits the load to the vertical support elements, depending on their axial rigidity. This causes the columns and walls to load considerably more than the props.

Table 1 shown the results of the axial stress on the most loaded prop at ground level, for each step of load.

\section{Transient Study of on Ground Floor Props}

Thanks to this transient study it is possible to evaluate the stress condition on the first floor slab after the construction stage which involves the removal of the ground floor props, represented in Fig. 8. During this action there is a change in the load path: Before removal, the load reached the ground thanks to a large number of props and pillars; after removal, the slab starts to flex, concentrating the uniformly distributed load on few pillars.

The sum of all axial loads coming from the props supporting the second floor, which is assimilable to a distributed load on the first floor slab, is greater than the one considered for the slabs design at the project state (without considering combining coefficients).

Because of this greater load, it is necessary to recheck the structural element using DM 2008 for bending (ULS), shear (ULS) and cracking (SLS) and using EC2 for punching (ULS), which is more detailed than in DM 2008. Given the temporary nature of this load condition, which will insist on the slab for a maximum of fifteen days, it is considered reasonable to reduce the combination coefficients for ULS, using 1,2 instead of 1,3 and 1,5 (NTC, 2008). Thanks to this reduction, the ULS checks (bending, shear and punching) are satisfied with a higher margin than the project state. On the other hand, the reduction cannot be applied to the SLS check, where the coefficients are 1,0 or less.

Figure 9 shown the bar chart of the values obtained for bending, shear, punching and cracking related to the limits imposed by the Code, at project state.

Results show how, during transitional phases of construction, considerable unforeseen cracks can be created, as shown from Fig. 10. They can negatively affect the durability of the structure.

Therefore, by means of a CS analysis, it can be possible to prevent durability problems and enhance the control's rate on solicitations that are, otherwise, unforeseeable. 


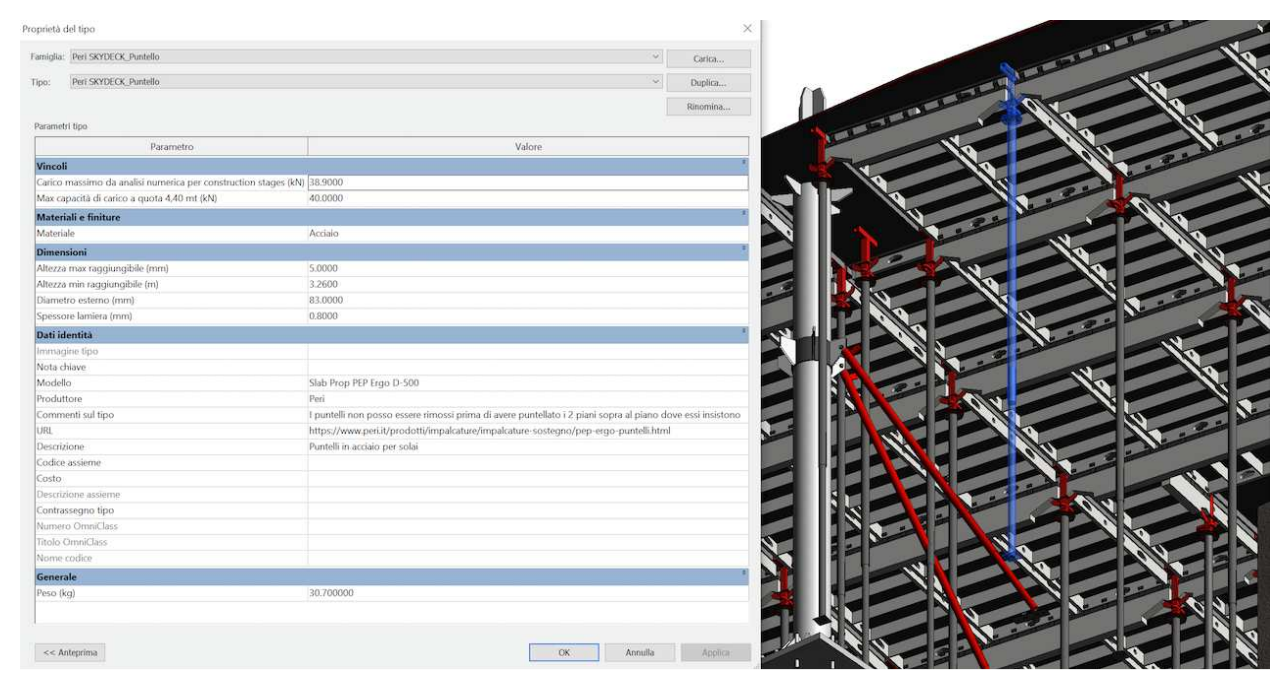

Fig. 5: BIM card of Peri props

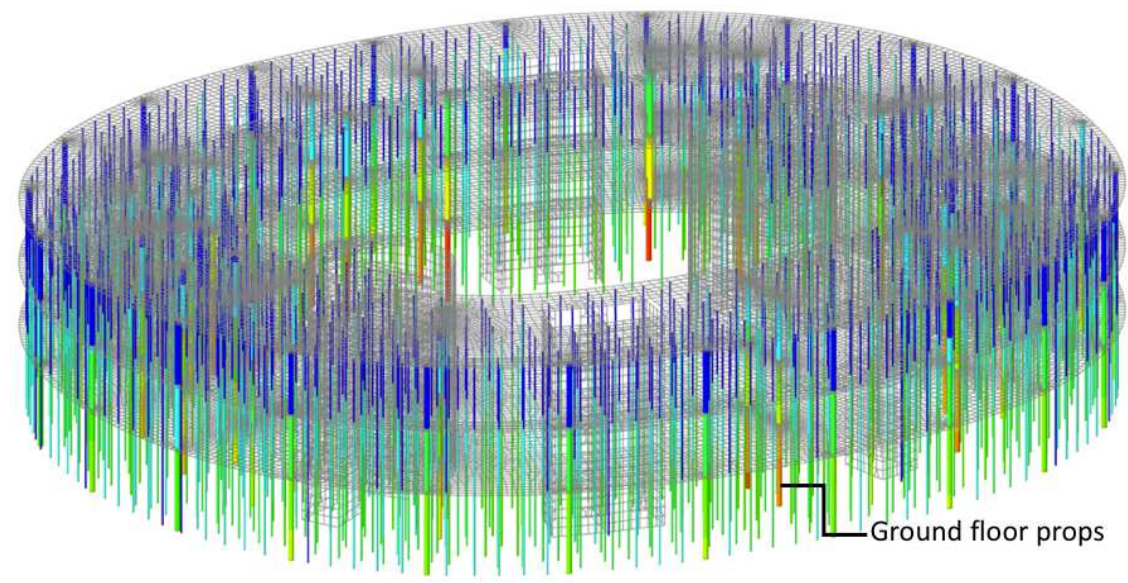

Fig. 6: FEM model - study of props stress condition (axial load on most stressed prop, $\mathrm{N}_{\mathrm{ed}}=38,9 \mathrm{kN}$ )

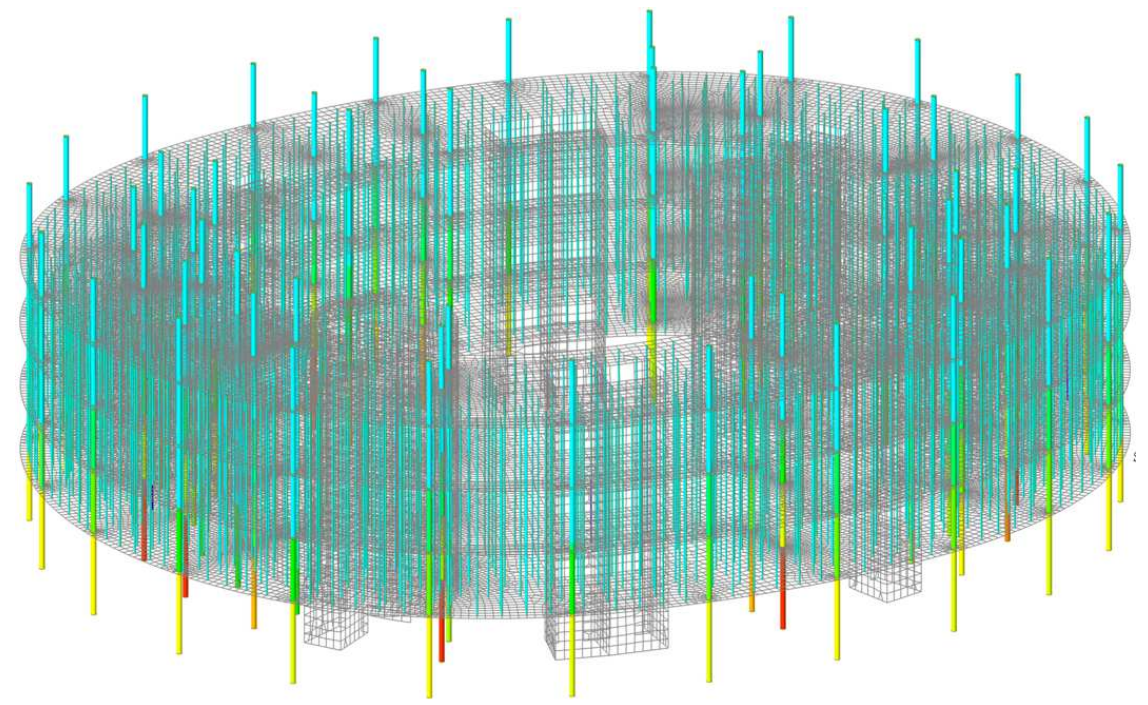

Fig. 7: FEM model - ground floor props removal 


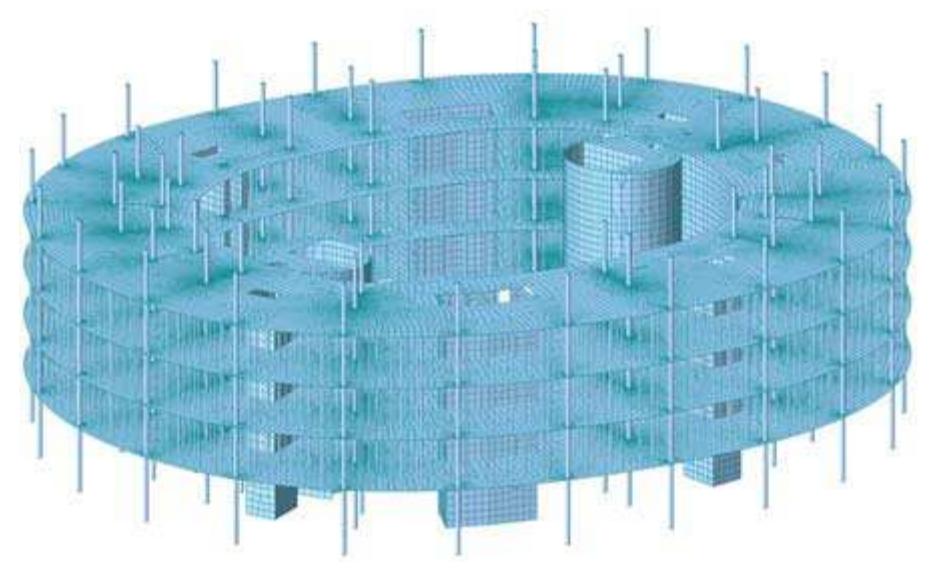

Fig. 8: Construction Stage: $1^{\circ}$ floor not supported by props

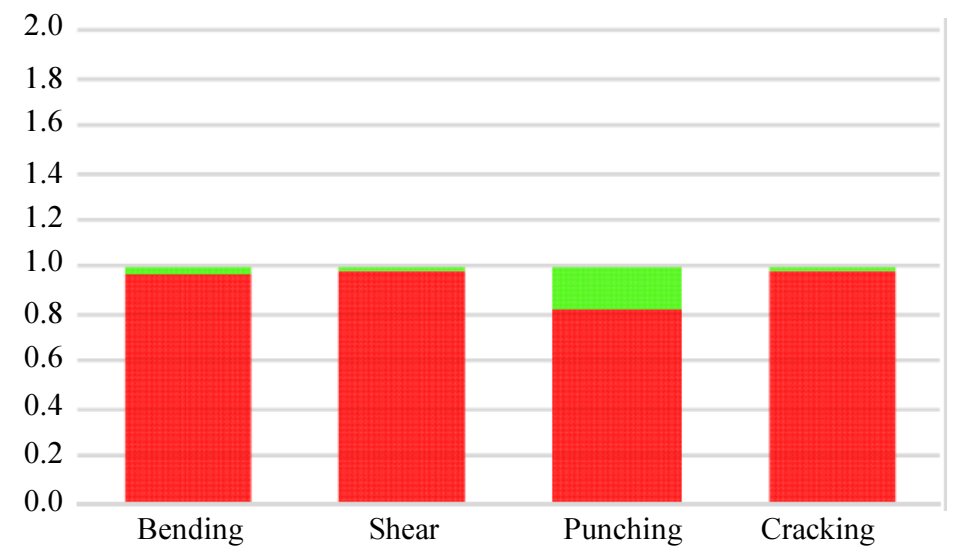

Fig. 9: Project state checks: In red the fraction between action and ULS limit; in orange the fraction between action and SLS limit

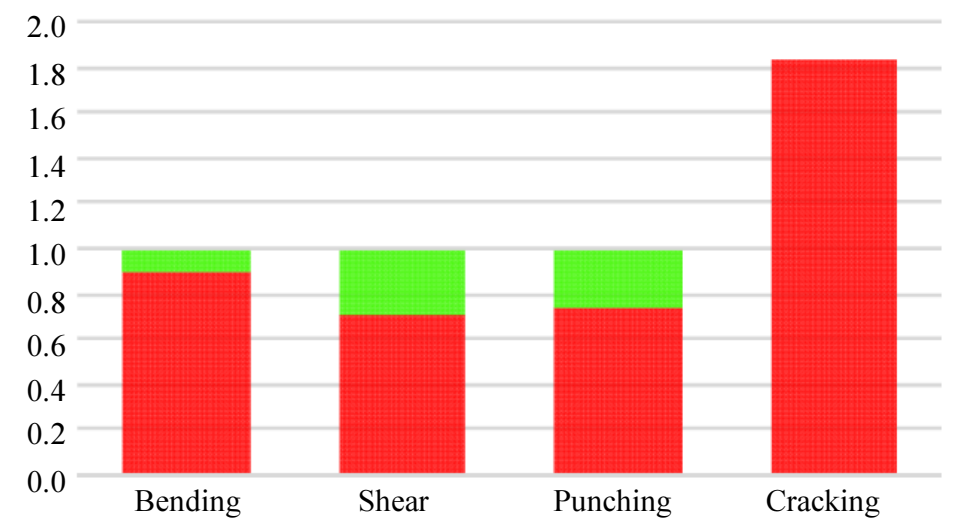

Fig. 10: Transitional checks: In red the fraction between action and ULS limit; in orange the fraction between action and SLS limit

Table 1: Stress condition of the most loaded prop at ground level

\begin{tabular}{lll}
\hline Ned $[\mathrm{kN}]$ & Stages & Time elapsed from $1^{\circ}$ floor slab's casting \\
\hline 21 & $1^{\text {st }}$ stage: $1^{\text {st }}$ floor casting & 0 days \\
21 & Execution of $1^{\text {st }}$ floor elevations. & 8 days \\
30 & 2nd stage: $2^{\text {nd }}$ floor casting & 15 days \\
30 & Execution of $2^{\text {nd }}$ floor elevations & 23 days \\
38,9 & $3^{\text {rd }}$ stage: Third floor casting & 30 days \\
38,9 & Execution of $3^{\text {rd }}$ floor elevations & 38 days \\
0 & Removal of ground floor props & 38 days \\
\hline
\end{tabular}




\section{Conclusion}

The aim of this study is to analyze the construction stages of an important building, evaluating its critical issues that emerged in a transitional study.

Before starting the CSA, it is necessary to gain greater awareness of the structural project, checking the main structural components. This has highlighted which were the most critical element. In particular, the safety factors resulting for slabs, beams and the foundation plate are near the limit value. On contrary, columns and walls are quite oversized for nonstructural reasons. As result, the transitional analysis is more thorough on these elements.

Once the preliminary check has been completed, the CSA is carried out using a FEM software combined with a BIM software for structural phases implementation. The first, thanks to the consideration of concrete maturation functions, has been useful to obtain all stress information of structural elements during each transitional step. All the information may be used to avoid unexpected situation during the construction phases. The second one shows, in a clear and

immediately understandable form, the 3D model of analyzed steps using BIM technology, useful to transmitting information extrapolated from the CSA directly to the site; furthermore it permits to split each phase in a sufficient number of sub-phases to clarify the exact construction sequence.

A further advantage of the CSA is to evaluate some

critical issues in a more detailed way. Various analyses have been carried out. One of the most interesting aspect regards the load history of the props; another one is the evaluation of the deformations in those structural elements interested by an evolution of the stress condition during the construction time (foundation, walls and columns). From these transitional checks it is possible to accurately evaluate some structural issue, unpredictable with a classic analysis and very often unattended in classic structural design approach.

The results difference between a CSA and a classic analysis, that consider only the complete structure with the load applied instantly, are slight considering only the final stage. Only $5 \%$ was recorded for deformations of foundation and only $12 \%$ on axial deformation of columns. In spite of this, the benefit of carrying out a CSA results in the possibility of extrapolate values, in terms of stresses and deformations, during each phase.

Another great advantage is represented by an accurate estimation of the loads influencing the total deformation of the building (resulting from the total load). It emerges that working loads, on the foundation, counts for the $26 \%$ of the total; whereas for the columns, they count for the $33 \%$ of the total. By knowing these percentages it is possible to dimension, in a more appropriate way, all that elements which will be positioned only after the end of structure realization, because they will only be affected by such deformation.

\section{Acknowledgement}

This paper was presented at the 6th International Workshop on Design in Civil and Environmental Engineering held at the University of Cagliari during November 9-10-11, 2017.

\section{Author's Contributions}

Marco Zucca and Nicola Logarini: Conceptual design and FEM implementation.

Federico de Socio and Iacopo Migliori: Finite Element Model, Revit Model implementation and Structural analysis.

\section{Ethics}

The manuscript report an original work not pubblished in other jornal. The corresponding author affirm that all of the other authors have read and approved of the manuscript.

\section{References}

Sacks, R., L. Koskela and B.A. Dave, 2010. Interaction of lean and building information modeling in construction. J. Construct. Eng. Manage.

Serena, R., 2012. Progetto di espansione del campus urbano: Nuovi spazi per l'università commerciale Luigi Bocconi sull'area ex centrale del latte. $\mathrm{PhD}$ Thesis.

NTC, 2008. Norme tecniche per le costruzioni. Italian National Annex.

CEB-FIB, 2010. Model code for concrete structures. 